\title{
THE FUTURE ROLE OF DESTINATION MANAGEMENT ORGANIZATIONS: THEORIES AND METHODOLOGICAL TOOLS
}

\author{
Iordanis Katemliadis \\ Senior Lecturer, City Unity College Nicosia, Nicosia, Cyprus, \\ e-mail: i.katemliadis@cityu.ac.cy
}

Received: 3 July 2020 / Revised: 5 July 2020 / Accepted: 8 July 2020 /

Published: 30 November 2020

\begin{abstract}
The aim of this paper is to review the existing literature regarding Destination Management Organizations (DMO) and the various stakeholders that the destination consists of. The paper covers the preliminary stage of the whole research which will cover existing theories such as business ecosystem and stakeholder theories and it will also suggest for future research a systemic approach towards destinations in order to improve their effectiveness and efficiency. Finally, it will examine the various methodological tools such as benchmarking and EFQM that exist and can be used in order to research the topic. The aim is to identify the need for future research to develop an optimal model of effective DMO.
\end{abstract}

Keywords: Benchmarking, Destination Management Organizations (DMOs), EFQM, stakeholder, tourism.

JEL code: $052, L 83, M 40$.

\section{Introduction}

Tourism is a worldwide industry, which especially after the recent economic crisis is considered very important in creating employment and boosting the economy at a local and national level. The World Tourism Organization (WTO) reported 1.235 billion arrivals and 1.4 trillion dollars' receipts for 2016. Regions and countries make extra efforts in order to make their destinations stand out from the competition and improve their competitiveness.

Furthermore, another major change is the fact that the industry has become even more complex and interrelated over the last years. While in the past the industry was dominated by tour operators, travel agencies and printed material, nowadays the emergence of Online Travel Agents (OTA's) and the concept of shared economy (Airbnb) has increased the competition among the industry players. It has also created more complex and interrelated relationships among the major stakeholders of the tourism system. Knowledge is in the centre of the above changes. McLeod and Vaughan $(2015$, p. 1) state that knowledge is "a key ingredient by which the tourism sector can adjust and adapt to its dynamic environment".

Destinations need to respond to all these changes and create a framework where all the stakeholders can work together to increase the 
effectiveness and efficiency of the destination and where all can benefit not to the detriment of the others. The power has also shifted from the supply side (businesses) to the demand side (tourists), and this is something that destinations need to bear in mind.

\section{Literature review Destination Management Organizations (DMOs)}

Any DMO is oriented to organize "the various components of the territory, guiding them towards a strategy and a common value through a planned, governed and collective process" (Varra et al., 2012). Several authors (Ritchie and Crouch, 2003; Dredge, 2006; Bornhorst et al., 2010; Volgger and Pechlaner, 2014; Pike and Page, 2014) suggest that the sustainable and competitive development of tourist destinations is highly related to the ability of the DMOs to manage destinations. The DMO does also play the role of enhancing uniqueness and authenticity of a destination increasing livelihood of it (Richard \& Palmer, 2010).

The success of any destination relies on its coordinated approach towards planning, development, controlling, management and marketing.

Prof. Richard W. Butler's work in 1980 started a discussion about tourism carrying capacity and sustainability. He saw the risk that tourism attractions are fragile and need to be carefully managed so that they are not allowed to exceed their capacity limits. After all, who wants to stay at a resort that feels overcrowded and over-commercialized? As Butler points out, tourism destinations carry with them the seeds of their own destruction. Thus, the concept of carrying capacity is rooted in a notion of "limits to growth". The notion of carrying capacity or sustainability yield has become a basic criterion of sustainability. Ecosystems and populations have a limited capacity to cope with environmental stress; above a certain amount of stress there may be detrimental effects for the ecosystems. Carrying capacity is defined as "the growth limits an area can accommodate without violating environmental capacity goals". Policies to regulate human activities and for anticipating environmental impacts can assist in attaining carrying capacity limits.

On this issue, a Destination Management Organization can contribute greatly in order to achieve all the above by using the latest technology of the Destination Management System (DMS) which provide a complete set of tourism management, promotion and fulfilment tools with product, business and visitor databases as its foundation. This enables DMOs to be able to promote their destination through any number of different platforms, including web and digital ones, call-centres, kiosks and smart devices by providing your visitor with detailed, real-time information at multiple 
locations. Tourists request a wide variety of information on places, facilities, attractions and activities at destinations before their departure. Thus, emphasis is placed on the speed and the ability of destination management to satisfy the needs and the wants of the clients by providing all the relevant, appropriate and accurate information by handling their reservations and requests promptly and efficiently. (Buhalis, 1997).

Destinations are also comprised of various stakeholders such as hotels, restaurants, travel agents, tour operators, government agencies and everyone who is operating in the destination and influence the supply or demand to a smaller or greater extent. Many of the above stakeholders though in many cases have conflicting interests, and therefore they can potentially affect the destination negatively.

Destination research has primarily focused on identifying and classifying relevant stakeholders, while less emphasis has been placed on stakeholders' behavioural patterns and actual influence (e.g Selin \& Chavez, 1995). Recent research has broadened the perspectives by focusing on salience (Sheehan \& Ritchie, 2005; Cooper, Scott \& Baggio, 2009) and interpretations of the influence and power of key stakeholders (Beritelli \& Laesser, 2011) by differentiating stakeholders based on their potential to threaten and to cooperate. Hotels and hotel associations were considered the most salient, followed by local and regional government. Cooper et al. (2009) found that destination management is controlled by a limited number of stakeholders, based on perceived salience, as key stakeholders form an elite at the core of its network.

DMOs need also to become the tools that can coordinate them and offer a vision and a holistic approach on how the destination can market, promote, protect the environment, minimize the negative impacts of tourism activities, respond to a crisis etc. The above are only a few of the contributions that a DMO can offer to a destination. This is the reason why DMOs play a leading role in most destinations. It takes a strategic approach to link-up very different entities for the better management of the destination, and this is something that only DMOs can offer.

DMOs are here to articulate a complex range of strategic objectives as well. Furthermore, in contrast to most private enterprises, DMOs focus not only on tourists but on the quality of life and residents of the host country/region. The latter is what makes it interesting and challenging and worth investigating further. 


\section{Stakeholders}

To define the term fairly and to capture the idea that any business, large or small, is about creating value for "those groups without whose support, the business would cease to be viable" (Freeman et al., 2010).

There is also a somewhat broader definition that captures the idea that if a group or individual can affect a business, then the executives must take that group into consideration in thinking about how to create value" (Freeman et al., 2010).

Stakeholders can affect or be affected by the organization's actions objectives and policies. Some examples of key stakeholders are creditors, directors, employees, governments, co-owners, suppliers or even the community from which the business draws its resources. However, not all stakeholders are equal. Freeman and Reed (1984) also define stakeholders as "those groups without whose support the organization would cease to exist. Table 1 contains some examples.

For somebody to understand the role and identify the involved stakeholders may be even more difficult, as the tourism industry comprises a complex network of stakeholders and groups that have an interest in the development, management and marketing of tourism for a destination. The support, commitment and cooperation of these stakeholders to tourism in a destination are essential for the long-term sustainability of the industry (Sustainable Tourism Online, 2009). Tourism stakeholder groups include industry operators, government departments and associations, visitors, the community, investors / developers, landowners, industry associations, tourism-related organizations, community and environmental groups.

All stakeholders need to participate in determining the direction of the organization in which they have a stake (Byrd, 2007). Stakeholders can be geographically dispersed, belong to the private or public sector and have little or significant participation in the destination's economy. Moreover, some stakeholders are more important than others in determining the success of activities (Dabphet, 2012). Effective stakeholder engagement must reduce potential conflicts between the tourists and the host community by involving the latter in shaping the way in which tourism develops (Macbeth, Burns, Chandler, Revitt, \& Veitch, 2002). Each group of stakeholders is a critical component of the tourism destination since the initiatives and thoughts of stakeholders are external to the strategic planning and management processes (Dill, 1975). 
Table 1. Various stakeholders (compiled by the authors)

\begin{tabular}{|c|c|}
\hline Stakeholders: & Stakeholder's concerns \\
\hline Government & $\begin{array}{l}\text { Taxation, VAT, legislation, employment, truthful reporting, diversity, } \\
\text { legalities, externalities. }\end{array}$ \\
\hline Employees & $\begin{array}{l}\text { Rates of pay, job security, compensation, respect, truthful } \\
\text { communication. }\end{array}$ \\
\hline Customers & Value, quality, customer care, ethical products. \\
\hline Suppliers & $\begin{array}{l}\text { Providers of products and services used in the end product for the } \\
\text { customer, equitable business opportunities. }\end{array}$ \\
\hline Creditors & Credit score, new contracts, liquidity. \\
\hline Community & $\begin{array}{l}\text { Jobs, involvement, environmental protection, shares, truthful } \\
\text { communication. }\end{array}$ \\
\hline Trade Unions & Quality, worker protection, jobs. \\
\hline Owner(s) & $\begin{array}{l}\text { Profitability, longevity, market share, market standing, succession } \\
\text { planning, raising capital, growth, social goals. }\end{array}$ \\
\hline Investors & Return on investment, income. \\
\hline
\end{tabular}

Inskeep (1991) explains that regarding implementation, the public sector is concerned with several functions such as arranging developments, carrying out rules and regulations on tourism, developing main infrastructure, advancing the appeal of public tourism and conducting marketing to promote tourism areas. In the meantime, Gunn (1994) elaborates that the public sector function within the tourism industry is to increase tourist satisfaction, enhance economic and business success, protect existing assets and preserve community integration. The public sector is also more involved in planning, enforcing laws related to tourism destinations and managing the construction of infrastructure as well as public tourism appeal.

The private sector on the other hand is more concerned about running profitable operations, developing new products, earning market share, improving the quality of services/products, and the longevity of their firm. Private firms are geared towards competing at all costs and regularly they have short term goals. Tribe (1997) makes a distinction between external and internal stakeholders, depending on the power and influence they have on the organization. He suggests that a hierarchy of stakeholders should be identified. This is the reason why stakeholder theory has become an important theoretical tool in the arsenal of the strategic management. It is a theory that can be applied to a wide range of issues and environments, and it will prove very useful in current research. 


\section{Expected contribution and the purpose of the study}

DMOs may be useful but they have been accused of being ineffective and too slow to adapt to new developments. It has also been proven too difficult to measure their efficiency and effectiveness. Even though a lot has been written about DMOs, what has not been analysed is a systemic approach that will include all stakeholders and measure the effectiveness and efficiency of these organizations. This approach will not include only specific sectors of the economy where tools like benchmarking and EFQM can be very useful, but it will take a systemic approach. In this case the stakeholder theory and the business ecosystem theory will prove very useful.

In this context, a methodological tool will be developed and applied in order to create new knowledge that will improve the efficiency and effectiveness of DMOs.

By improving the effectiveness and efficiency of DMOs, we help the destination as well to improve the good use of the resources that the stakeholders possess and as a result improve their performance (e.g. return on investment)

The successful function of DMOs can improve the competitiveness of the destination and place the destination in a leading/ strong position among competing destinations. That will strengthen the competitiveness of the businesses that are an integral part of the destination with subsequent positive impacts on the local community.

By also developing the tools and methodology, authorities will be able to monitor and control the issue of the carrying capacity as well as the efficiency of the destination on a regular basis and do the necessary adjustments when needed.

Furthermore, DMOs can do a lot more for the local community. That was also the main reason of choosing this topic of the research and that would be the ultimate result and contribution which this research could provide.

By mitigating among the stakeholders, DMOs can minimize the negative effects of tourism activities. They can protect the community from the degradation of the environment, minimize sociocultural side effects, help to alleviate the problem of seasonality and establish a sustainable way of how businesses operate.

By improving the function of DMOs, the local communities will be able to reap the maximum possible benefits of tourism development and minimize the negative side effects.

Finally, and very importantly, various stakeholders including local communities will be included more actively in the decision-making process on issues regarding the development of their region. 


\section{Research methodology Research Process and questions}

There are several researches associated with DMOs in relation to the various stakeholders like airlines, hotels etc. There is a lack of research though taking a systemic approach towards the destination, which is very important, since every stakeholder affects the destination to a smaller or greater extent. There are several DMOs operating privately or state funded, but there is no systemic approach towards measuring their effectiveness. There are performance indicators measuring the effectiveness of marketing or advertising campaigns but not a method to measure their overall performance. In this way, public money might not be properly allocated and private investments might not offer the return on investment (ROI) that they could.

Future research could shed light onto the complex inner workings of a destination and how interrelated organizations (e.g. hotels, government agencies,) affect each other. The research could also provide practical tips on how various and very often conflicting firms can work together and align their strategies. The result of this research could be a tool/framework that will be used in various environments and occasions in order to measure the effectiveness and efficiency of DMOs.

\section{Methods}

There are various methodologies, tools and approaches that can be used. A descriptive study can be undertaken in order to ascertain and be able to describe the characteristics of the variables of interest in a situation (Sekaran, 2000). The focus is not on the explanation (Veal, 2011). In this type of research, relevant aspects of the research topic can be described.

With the explanatory research, the researcher is trying to establish how one phenomenon is influenced by another (Veal, 2011). This is where a researcher has an idea or has observed something and seeks to understand more about it (Kowalczyk, 2014). Exploratory research helps to determine the best research design and data collection method (Shields, Patricia and Rangarjan, N., 2013). Moreover, it often relies on secondary research such as reviewing available literature and/or data, or qualitative approaches such as informal discussions with employees, management or competitors, and more formal approaches through in-depth interviews, focus groups, projective methods, case studies or pilot studies.

The descriptive research can describe the terms of effectiveness and DMO, but the explanatory can establish how DMOs and efficiency are related. 
Another type of research that can be used is evaluative. By using evaluative research, we assess the success of a policy or management action. In this case the effectiveness and efficiency of various DMOs and how well they perform could be evaluated.

All the above-mentioned types have qualitative and quantitative characteristics. Van Maaten (1983) defines qualitative methods as "an array of interpretive techniques which seek to describe, decode, translate and otherwise come to terms with the meaning, not the frequency of certain more or less naturally occurring phenomena in the social world". The qualitative methods that will be used are in-depth interviewing and analysis of texts.

Veal (2011) states that quantitative research is a kind of research in which, numbers are the main medium. We use statistical, mathematical, numerical data or computational techniques. The objective of quantitative research is to develop and employ mathematical models, theories and/or hypotheses pertaining to the phenomena.

The proposed research could also have more of an applied scope than a theoretical one. It can seek to address a policy/management issue in contrast to research that will only result in general propositions. It will seek to address the issue of how to improve the efficiency of DMOs. The research can also work on an empirical and non-empirical level. Any future research can involve data (empirical) using quantitative and qualitative data, but it can use also theory and the literature (non-empirical).

The research can be more inductive in nature since new tools and theories might be created from the examination of data collected from the field. Therefore, primary data will be used, which will be gathered by the researcher (Veal, 2011), but also when appropriate secondary data will be gathered.

During the research, private and state-owned destination management companies can be contacted. Moreover, major stakeholders of the region such as airlines, hotel and hotel associations which, play a major role in forming strategies and influence decisions in tourism destinations, will be contacted.

The detailed steps of the methodology are proposed to be as the following:

Detailed comprehension and analysis of the bibliography concerning destination management, destination management organizations (DMOs), stakeholder theory, benchmarking, the EFQM excellence model, business ecosystems. Analysis of case studies that have been written concerning the tourism sector, previous PhDs written on relevant topics and research on the Internet, magazines and newspapers. Also, at this point destination management organizations will be examined to identify the key characteristics that they have in common. 
Identification of tools that have been used to measure effectiveness and identify all the necessary theory regarding economic models, statistical models that will be used in the research process. More specifically in the context of business ecosystems theory and stakeholder theory, we will use two benchmarking techniques: The Data Envelopment Analysis (DEA) and the Stochastic Frontier Analysis (SFA).

The DEA technique is appropriate for our research since it determines the efficiency of the object (e.g. businesses) participating in the benchmarking process. It is a non-parametric technique to measure productivity with multiple inputs and outputs. The destination is exactly a place where multiple stakeholders with various inputs are involved and produce numerous outputs. Furthermore, the DEA technique uses variable weights, and this is in line with the fact that each stakeholder has a different level of influence. Finally, the DEA technique gives the researcher the opportunity to analyse and quantify the sources of inefficiency for every evaluated unit (Cook, Tone, and Zhu, 2014). On the other hand, we must also be aware of the shortcomings of this technique.

The SFA is a parametric technique that uses standard production function methodology. It may be used in modelling functional relationships where you have theoretical bounds. The SFA is used to model producer behaviour, where a producer in our case can be any of the stakeholders participating in the destination business ecosystem.

The advantage of the SFA technique is that it produces efficiency estimates or efficiency scores of individual producers. Therefore, this technique will be used in order to identify inefficiency issues for each stakeholder that need corrective measures. Moreover, since efficiency scores vary across producers, they can be related to producers' characteristics such as ownership and size. This advantage gives us also the chance to relay this technique to each stakeholder's specific features. Finally, the SFA technique provides us with a powerful tool to examine effects of intervention. By using the above technique, the future researcher will be able to examine any changes that are made by any of the important stakeholders within the destination.

\section{Conclusions}

DMOs work as the link between supply and demand. They promote marketing and build the image of the destination. They also gather data and use the information from customers and disseminate it to the various interested stakeholders. Nowadays though, they need to move from just marketing and management organizations to intelligent agents and knowledge gatekeepers. They also need to be able to respond swiftly to a 
crisis and above all to act as intermediaries and coordinators among the stakeholders.

From the above we clearly understand the complexity of the role that DMOs need to play. Therefore, their effectiveness and efficiency in executing the above roles is of great importance to all stakeholders.

From the above it is clear that any future research on the topic should focus more on how to improve the efficiency and effectiveness of those organizations. That is even more important if we take into consideration the fact the governments are limiting the resources that are allocating to DMOs.

\section{References}

1. Beritelli, P. (2011). Tourist destination governance through local elites: Looking beyond the stakeholder level (Doctoral dissertation, Universität St. Gallen)

2. Bornhorst, T., Ritchie, J. B., \& Sheehan, L. (2010). Determinants of tourism success for DMOs \& destinations: An empirical examination of stakeholders' perspectives. Tourism management, 31(5), 572-589.

3. Buhalis, D. (1997). Information technology as a strategic tool for economic, social, cultural and environmental benefits enhancement of tourism at destination regions. Progress in tourism and hospitality research, 3(1), 71-93.

4. Butler, R. W. (1980). The concept of a tourist area cycles of evolution: implications for management of resources. Canadian Geographer/Le Géographe canadien, 24(1), 5-12

5. Byrd, E. T. (2007). Stakeholders in sustainable tourism development and their roles: applying stakeholder theory to sustainable tourism development. Tourism review

6. Cook, W. D., Tone, K., \& Zhu, J. (2014). Data envelopment analysis: Prior to choosing a model. Omega, 44, 1-4.

7. Dabphet, S., Scott, N., \& Ruhanen, L. (2012). Applying diffusion theory to destination stakeholder understanding of sustainable tourism development: A case from Thailand. Journal of Sustainable Tourism, 20(8), 1107-1124.

8. Dredge, D., Jenkins, J., \& Whitford, M. (2011). Tourism planning and policy: Historical development and contemporary challenges. Stories of practice: tourism policy and planning, 13-35.

9. Easterby-Smith, M., Araujo, L., \& Burgoyne, J. (Eds.). (1999). Organizational learning and the learning organization: Developments in theory and practice. Sage.

10. Freeman, R. E., \& Reed, D. L. (1983). Stockholders and stakeholders: A new perspective on corporate governance. California management review, 25(3), 88-106.

11. Freeman, R. E., Harrison, J. S., Wicks, A. C., Parmar, B. L., \& De Colle, S. (2010). Stakeholder theory: The state of the art. Cambridge University Press

12. Gunn, B. (1994). A participative management approach to case analysis. Performance+ Instruction, 33(5), 32-43.

13. Inskeep, E. (1991). Tourism planning: an integrated and sustainable development approach. Van Nostrand Reinhold

14. Kowalczyk, A. (2014). The phenomenology of tourism space. Turyzm, 24(1), 9-15.

15. McLeod, M., \& Vaughan, R. (Eds.). (2014). Knowledge networks and tourism. Routledge. 
16. Pike, S., \& Page, S. J. (2014). Destination Marketing Organizations and destination marketing: A narrative analysis of the literature. Tourism management, 41, 202-227.

17. Richards, G. (2014). Creativity and tourism in the city. Current issues in Tourism, 17(2), 119-144.

18. Ritchie, J. B., \& Crouch, G. I. (2003). The competitive destination: A sustainable tourism perspective. Cabi.

19. Sekaran, U., \& Bougie, R. (2016). Research methods for business: A skill building approach. John Wiley \& Sons

20. Selin, S., \& Chevez, D. (1995). Developing a collaborative model for environmental planning and management. Environmental management, 19(2), 189-195.

21. Sheehan, L. R., \& Ritchie, J. B. (2005). Destination stakeholders exploring identity and salience. Annals of Tourism Research, 32(3), 711-734.

22. Sheehan, L., Sánchez, A. V., Presenza, A., \& Abbate, T. (2015, August). The Intelligent Destination Management Organization. In Toulon-Verona Conference" Excellence in Services"

23. Shields, P., \& Rangarajan, N. (2013). Research Methods: Integrating Conceptual Frameworks and Project Management.

24. Stabler, M. J., Papatheodorou, A., \& Sinclair, M. T. (2009). The economics of tourism. Routledge

25. Tribe, J. (1997). The indiscipline of tourism. Annals of tourism research, 24(3), 638657.

26. UNWTO (2013). Governance for the Tourism Sector and its Measurement. Madrid: UNWTO

27. Varra, L., Buzzigoli, C., \& Loro, R. (2012). Innovation in destination management: Social dialogue, knowledge management processes and servant leadership in the tourism destination observatories. Procedia-Social and Behavioral Sciences, 41, 375385.

28. Veal, A. J. (2011). Research methods for leisure and tourism: A practical guide. 4th edition

29. Volgger, M., \& Pechlaner, H. (2014). Requirements for destination management organizations in destination governance: Understanding DMO success. Tourism Management, 41, 64-75. 